OPEN ACCESS

Edited by:

Wen Zhou,

Case Western Reserve University,

United States

Reviewed by:

Mehdi Hedayati,

Shahid Beheshti University of Medical

Sciences, Iran

Cristina Romei,

University of Pisa, Italy

*Correspondence:

Anders Würgler Hansen

anders.wurgler.hansen@rsyd.dk

Specialty section: This article was submitted to

Cancer Endocrinology,

a section of the journal

Frontiers in Endocrinology

Received: 21 July 2020 Accepted: 03 September 2020

Published: 14 October 2020

Citation:

Würgler Hansen A, Sønderberg Roos LK, Løss/ K, Godballe C and Mathiesen JS (2020) Preimplantation Genetic Testing of Multiple Endocrine Neoplasia Type 2A.

Front. Endocrinol. 11:572151 doi: 10.3389/fendo.2020.572151

\section{Preimplantation Genetic Testing of Multiple Endocrine Neoplasia Type 2A}

\author{
Anders Würgler Hansen 1,2*, Laura Kirstine Sønderberg Roos ${ }^{3}$, Kristine Løss/ ${ }^{4}$, \\ Christian Godballe ${ }^{5,6}$ and Jes Sloth Mathiesen ${ }^{5,6}$
}

${ }^{1}$ Faculty of Health Sciences, University of Southern Denmark, Odense, Denmark, ${ }^{2}$ The Emergency Department, Sydvestiysk Sygehus, Esbjerg, Denmark, ${ }^{3}$ Department of Clinical Genetics, Copenhagen University Hospital Rigshospitalet, Copenhagen, Denmark, ${ }^{4}$ The Fertility Clinic, Copenhagen University Hospital Rigshospitalet, Copenhagen, Denmark, ${ }^{5}$ Department of ORL Head and Neck Surgery and Audiology, Odense University Hospital, Odense, Denmark, ${ }^{6}$ Department of Clinical Research,

University of Southern Denmark, Odense, Denmark

Background: When discussing matters of reproduction, the 2015 revised guidelines for the management of medullary thyroid carcinoma recommend that patients diagnosed with multiple endocrine neoplasia type 2A (MEN 2A) are informed about the option of Preimplantation Genetic Testing for Monogenic Disorders (PGT-M). In addition, patients seem to have a genuine interest in reproductive options. However, there are just two reports worldwide of this technology being used for patients with MEN 2A. We here present, in a Danish couple where the man has MEN 2A, the first European family with children born after PGT-M.

Objective: To report the results of PGT-M in relation to multiple endocrine neoplasia type $2 \mathrm{~A}$ with the aim to increase awareness among physicians treating this and other genetic disorders.

Methods: A Danish couple was referred to the PGT Center at Copenhagen University Hospital Rigshospitalet and opted for PGT-M after counseling by a clinical geneticist and a fertility doctor. The embryos were diagnosed using microsatellite polymorphic marker close to RET.

Results: The couple had two healthy children born in 2017 and 2019 as a result of a total of three ICSI treatments including controlled ovarian stimulation, oocyte retrieval and PGT-M, and a total of six blastocyst transfers.

Conclusion: A session with a clinical geneticist covering all reproductive options for patients in early adult life is a relevant part of the clinical management of patients with MEN 2A, and other patients with hereditary cancer predisposition syndromes.

Keywords: PGT-M, assisted reproductive technology, rearranged during transfection (RET), medullary thyroid carcinoma, multiple endocrine neopasia type 2

\section{INTRODUCTION}

Multiple endocrine neoplasia type 2 (MEN 2) is an autosomal dominant inherited cancer syndrome. MEN 2 is caused by germline mutations of the REarranged during Transfection (RET) proto-oncogene $(1,2)$. The syndrome comprises MEN 2A and MEN 2B. MEN 2A accounts for $\sim 95 \%$ of MEN 2 cases and has an estimated point prevalence of 1:42.000-80.000 (3-6). MEN 2A is 
characterized by the propensity to develop medullary thyroid cancer (MTC), pheochromocytoma, primary hyperparathyroidism, cutaneous lichen amyloidosis and Hirschsprung disease. While virtually all patients develop MTC, the remaining features occur less frequently. Left untreated, MEN $2 \mathrm{~A}$ has devastating consequences. Accordingly, prophylactic total thyroidectomy is often recommended at an early age. The recommended timing of the surgery is largely dictated by the genotype and by serum calcitonin levels. The intervention follows lifelong monitoring of paraclinical markers (6).

For individuals with MEN 2A, the probability of passing on the pathogenic RET-variant to their offspring is $50 \%$. Preimplantation Genetic Testing for Monogenic Disorders (PGT-M) in combination with assisted reproduction technology (ART) is an available reproductive option for couples with MEN 2A. PGT-M is performed to deselect embryos carrying a pathogenic $R E T$-variant prior to implantation. In 2015, the American Thyroid Association issued revised guidelines for medullary thyroid carcinoma (6). Here, clinicians were recommended to inform patients with MEN 2 about the availability of PGT-M and refer to a clinical geneticist. Adding to this, patients seem to have a genuine interest in PGT-M in relation to reproduction (7). However, just two cases have been reported so far and none originated from Europe $(8,9)$. Aiming to increase awareness among physicians treating this and other genetic disorders, especially in Europe, of the possibility for PGT$M$ in MEN 2A patients, we here report the first European case. Informed written consent has been obtained from the family for publication of the case report.

\section{CASE}

In 2000, a Danish family was diagnosed with MEN 2A with Hirschsprung, due to the presence of the RET, c.1858T $>C$, p.C620R germline variant, Hirschsprung's disease and MTC. The family was unrelated to other previously reported Danish families carrying the same variant $(10,11)$. In this family, a then 11-year old boy tested positive for the RET C620R variant. He had a basal calcitonin of $0.42 \mu \mathrm{g} / \mathrm{L}(<0.1 \mu \mathrm{g} / \mathrm{L})$ at the time and underwent prophylactic total thyroidectomy and neck dissection, revealing a T1aN1bM0 MTC. The following four years, the calcitonin level slowly increased to $153 \mathrm{ng} / \mathrm{L}(<10.5 \mathrm{ng} / \mathrm{L})$ but has now for the last 15 years remained stable despite the fact that no additional treatment has been given.

In 2015, following thorough counseling by a clinical geneticist, the then 26-year old man and his 25-year old partner were referred to the PGT Center at The Copenhagen University Hospital Rigshospitalet, Denmark. His partner was overall healthy. The couple underwent thorough genetic counseling by a clinical geneticist and information about reproductive options, including both PGT-M, spontaneous conception with prenatal diagnosis, sperm donation and adoption was given. The couple decided on PGT-M and was referred to treatment.

In preparation for the genetic analysis of embryo biopsy, a semi-informative microsatellite polymorphic marker was identified (D10S1669). Based on genomic DNA from family members and the female partner, haplotypes were constructed. Linkage analysis was performed using multiplex PCR as previously described (12). Thereby the embryos expecting to carry the C620R variant could be identified and deselected.

Assisted reproduction technology including controlled ovarian stimulation, oocyte retrieval, intracytoplasmic sperm injection (ICSI), in vitro culture and embryo biopsy (nowadays blastocyst) is a prerequisite for PGT. In this case, the woman underwent a total of three fresh ICSI treatments that resulted in a total of 25 cleavage stage embryos that could undergo biopsy. After genetic analyses, a total of nine embryos were expected not to carry the pathogenic RET-variant.

In November 2017, the first pregnancy was achieved after a total of three ICSI treatments and five blastocyst transfers and resulted in the birth (GA 41+2) of a healthy girl with a birthweight of $3022 \mathrm{~g}$ and a length of $50 \mathrm{~cm}$. The couple returned in October 2018 for replacement of one of the two remaining usable blastocysts, which resulted in an ongoing pregnancy and the delivery (GA 41+3) of a healthy girl with a birthweight of $4,290 \mathrm{~g}$ and a length of $54 \mathrm{~cm}$. One useable blastocyst remains vitrified. None of the children carry the RET C620R variant or suffer from notable illnesses.

\section{DISCUSSION}

When PGT was introduced in 1990, the technology became an alternative approach to traditional prenatal diagnosis in cases where there is a known high risk of a genetically affected fetus due to known familial monogenetic variants (PGT-M) or structural chromosomal rearrangements (PGT-SR) (13-15). Further, PGT can be used to investigate embryos for numerical chromosomal aberrations or aneuploidies (PGT-A) in situations with no known familial genetic disease or as a supplement to PGT-M. Now, PGT is performed on a large scale at specialized facilities worldwide. The technology remains an ethical hot topic, as its use becomes continuously more widespread (16). Importantly, the crucial argument for using PGT lies in the wish to spare future offspring from the burden of a severe disease and NOT in eugenic considerations. Prenatal testing and PGT both focus on deselecting an embryo or fetus carrying a specific disease, rather than treating the disease. A clear advantage of PGT compared to prenatal testing is avoiding the risk of an ethical dilemma in deciding whether to terminate a pregnancy (17). By averting the transmission of a pathogenic RET-variant from affected individuals to their offspring, PGT can reduce the disease burden for future generations. Consequently, if applied routinely and consistently as a reproductive option, this technology can limit the population prevalence of MEN 2A, as de novo variants are regarded as rare (18). However, so far, the use of PGT in relation to MEN 2A has been limited as there are just two cases reported in the literature. In 2011, Altarescu et al. reported of an Israeli woman with MEN 2A, who by the use of PGT-M, gave birth to genetically unaffected dizygotic twins (8). Chen et al. presented a similar case of PGT-M in a Chinese couple where the male had MEN 2A (9). Unlike some other countries, in Denmark PGT is not reserved for specific diseases for which the procedure has 
been approved $(19,20)$. In each individual case the final decision to offer PGT is made by a clinical geneticist and is based on an assessment of the severity of the given disease.

A questionnaire issued by The University of Texas addressed individuals with hereditary cancer syndromes including MEN 2 who had visited a genetic counselor at this institution. Participants were asked about their awareness and acceptance of the PGT (7). Just $24 \%$ of the respondents were aware of PGT and individuals of a lower socio-economic status were particularly ill-informed. These results indicate a lack of knowledge among individuals who might stand to benefit from PGT. In addition, $72 \%$ felt that PGT should be offered and $43 \%$ would consider availing themselves of the technology. An obvious limitation to the study is a low response rate of $38 \%$. However, a comprehensive systematic review with meta-analysis found similar results (21).

Acceptance of PGT may be influenced by multiple sociodemographic and personal variables e.g., age, sex, religious affiliation, health care set-up, income, and medical history $(7,17,21,22)$. Firstly, certain religious beliefs may affect individuals stand on the PGT (7). Religious spokespersons have previously voiced strong opinions against the ethical aspects of PGT and some compare it to abortive practices (23). In many cases, however, PGT is considered an acceptable option, when pregnancy termination, or gamete donation is not compatible with ethical and religious beliefs. Secondly, PGT is a costly procedure which may influence patients' attitudes toward PGT (22). It is likely cost-effective as it may allow for substantial long-term savings being made in diagnosis and treatment (23). The procedure, however, is in some countries not covered by the state or by a standard health insurance. With a success rate of PGT in terms of clinical pregnancy as an outcome measure of $\sim 40 \%$ per embryo transfer, multiple cycles are often needed to result in a live birth $(15,24)$. Lastly, the perception that MEN

\section{REFERENCES}

1. Mulligan LM, Kwok JB, Healey CS, Elsdon MJ, Eng C, Gardner E, et al. Germline mutations of the RET proto-oncogene in multiple endocrine neoplasia type 2A. Nature. (1993) 363:458-60. doi: 10.1038/363458a0

2. Donis-Keller H, Dou S, Chi D, Carlson KM, Toshima K, Lairmore TC, et al. Mutations in the RET proto-oncogene are associated with MEN 2A and FMTC. Hum Mol Genet. (1993) 2:851-6. doi: 10.1093/hmg/2.7.851

3. Machens A, Lorenz K, Sekulla C, Hoppner W, Frank-Raue K, Raue F, et al. Molecular epidemiology of multiple endocrine neoplasia 2: implications for RET screening in the new millenium. Eur J Endocrinol. (2013) 168:307-14. doi: 10.1530/EJE-12-0919

4. Mathiesen JS, Kroustrup JP, Vestergaard P, Stochholm K, Poulsen PL, Rasmussen $\mathrm{AK}$, et al. Incidence and prevalence of multiple endocrine neoplasia 2A in Denmark 1901-2014: a nationwide study. Clin Epidemiol. (2018) 10:1479-87. doi: 10.2147/CLEP.S174606

5. Opsahl EM, Brauckhoff M, Schlichting E, Helset K, Svartberg J, Brauckhoff K, et al. A nationwide study of multiple endocrine neoplasia type $2 \mathrm{a}$ in norway: predictive and prognostic factors for the clinical course of medullary thyroid carcinoma. Thyroid. (2016) 26:1225-38. doi: 10.1089/thy.2015.0673

6. Wells SA, Jr., Asa SL, Dralle H, Elisei R, Evans DB, et al. Revised American Thyroid Association guidelines for the management of medullary thyroid carcinoma. Thyroid. (2015) 25:567-610. doi: 10.1089/thy. 2014.0335
$2 \mathrm{~A}$ can be managed by timely surgery with a potentially curative outcome may restrain patients from choosing PGT. Higher levels of acceptance have namely been documented among patients with diseases without available risk-reduction surgery (7). The risk reduction surgery of prophylactic total thyroidectomy is a cornerstone in the management of MEN 2A which is a measure taken to help prevent otherwise almost inevitable cancer disease from occurring (6). However, important points are the facts that this surgical intervention does not protect against other clinical manifestations of MEN 2A other than MTC, it does not remove the risk of persistent or recurring MTC and it is associated with risks of postoperative complications (25-29).

\section{CONCLUSION}

In this case report, we present the first case of successful PGT-M in MEN 2A in Europe. It may serve to remind clinicians following these patients of the possibility of PGT-M. A session with a clinical geneticist covering all reproductive options for patients in early adult life is a relevant part of the clinical management of patients with MEN 2A, and other patients with hereditary cancer predisposition syndromes.

\section{ETHICS STATEMENT}

Written informed consent was obtained from the individual(s) for the publication of any potentially identifiable images or data included in this article.

\section{AUTHOR CONTRIBUTIONS}

All authors drafted, critically revised, and gave final approval of the manuscript.

7. Rich TA, Liu M, Etzel CJ, Bannon SA, Mork ME, Ready K, et al. Comparison of attitudes regarding preimplantation genetic diagnosis among patients with hereditary cancer syndromes. Fam Cancer. (2014) 13:291-9. doi: 10.1007/s10689-013-9685-0

8. Altarescu G, Barenholz O, Renbaum P, Beeri R, Levy-Lahad E, Margalioth EJ, et al. Preimplantation genetic diagnosis (PGD)-prevention of the birth of children affected with endocrine diseases. J Pediatr Endocrinol Metab. (2011) 24:543-8. doi: 10.1515/jpem.2011.262

9. Chen S, Li S, Zhang J, Zhang L, Chen Y, Wang L, et al. Preimplantation genetic diagnosis of multiple endocrine neoplasia type $2 \mathrm{~A}$ using informative markers identified by targeted sequencing. Thyroid. (2018) 28:281-7. doi: 10.1089/thy.2017.0200

10. Mathiesen JS, Kroustrup JP, Vestergaard P, Stochholm K, Poulsen PL, Rasmussen AK, et al. Founder effect of the RET(C611Y) mutation in multiple endocrine neoplasia 2a in denmark: a nationwide study. Thyroid. (2017) 27:1505-10. doi: 10.1089/thy.2017.0404

11. Hansen HS, Torring H, Godballe C, Jager AC, Nielsen FC. Is thyroidectomy necessary in RET mutations carriers of the familial medullary thyroid carcinoma syndrome? Cancer. (2000) 89:863-7. doi: 10.1002/1097-0142(20000815)89:4<863::AIDCNCR19>3.0.CO;2-Z

12. Harton GL, De Rycke M, Fiorentino F, Moutou C, SenGupta S, Traeger-Synodinos J, et al. ESHRE PGD consortium best practice guidelines for amplification-based PGD. Hum Reprod. (2011) 26:33-40. doi: 10.1093/humrep/deq231 
13. Handyside AH, Kontogianni EH, Hardy K, Winston RM. Pregnancies from biopsied human preimplantation embryos sexed by Y-specific DNA amplification. Nature. (1990) 344:768-70. doi: 10.1038/344768a0

14. Verlinsky Y, Pergament E, Strom C. The preimplantation genetic diagnosis of genetic diseases. J In Vitro Fert Embryo Transf. (1990) 7:1-5. doi: 10.1007/bf01133875

15. De Rycke M, Goossens V, Kokkali G, Meijer-Hoogeveen M, Coonen E, Moutou C. ESHRE PGD Consortium data collection XIV-XV: cycles from January 2011 to December 2012 with pregnancy follow-up to October 2013. Hum Reprod. (2017) 32:1974-94. doi: 10.1093/humrep/dex265

16. Daley GQ, Lovell-Badge R, Steffann J. After the storm - a responsible path for genome editing. N Engl J Med. (2019) 380:897-9. doi: 10.1056/NEJMp1900504

17. Lammens C, Bleiker E, Aaronson N, Vriends A, Ausems M, Jansweijer M, et al. Attitude towards pre-implantation genetic diagnosis for hereditary cancer. Fam Cancer. (2009) 8:457-64. doi: 10.1007/s10689-009-9265-5

18. Schuffenecker I, Ginet N, Goldgar D, Eng C, Chambe B, Boneu A, et al. Prevalence and parental origin of de novo RET mutations in multiple endocrine neoplasia type $2 \mathrm{~A}$ and familial medullary thyroid carcinoma. Am J Hum Genet. (1997) 60:233-7.

19. Danish Patient Safety Authority. Assisted Reproduction. (2015). https://en.stps. dk/en/ [Accessed August 14 2020].

20. Bayefsky M. Who should regulate preimplantation genetic diagnosis in the United States? AMA J Ethics. (2018) 20:E1160-7. doi: 10.1001/amajethics.2018.1160

21. Quinn GP, Pal T, Murphy D, Vadaparampil ST, Kumar A. High-risk consumers' perceptions of preimplantation genetic diagnosis for hereditary cancers: a systematic review and meta-analysis. Genet Med. (2012) 14:191200. doi: 10.1038/gim.0b013e31822ddc7e

22. Genoff Garzon MC, Rubin LR, Lobel M, Stelling J, Pastore LM. Review of patient decision-making factors and attitudes regarding preimplantation genetic diagnosis. Clin Genet. (2018) 94:22-42. doi: 10.1111/cge.13174

23. Burton A. Controversy surrounds the selection of embryos to avoid cancer. Lancet Oncol. (2009) 10:545. doi: 10.1016/s1470-2045(09) 70150-0
24. Hreinsson J, Iwarsson E, Hanson C, Grondahl ML, Lossl K, Hyden-Granskog $\mathrm{C}$, et al. Preimplantation genetic testing practices in the Nordic countries. Acta Obstet Gynecol Scand. (2020) 99:707-15. doi: 10.1111/aogs.13821

25. Bussieres V, Roy S, Deladoey J, Rousseau E, St-Vil D, Piche N. Prophylactic thyroidectomies in MEN2 syndrome: Management and outcomes. J Pediatr Surg. (2018) 53:283-5. doi: 10.1016/j.jpedsurg.2017.11.015

26. Frank-Raue K, Buhr H, Dralle H, Klar E, Senninger N, Weber T, et al. Longterm outcome in 46 gene carriers of hereditary medullary thyroid carcinoma after prophylactic thyroidectomy: impact of individual RET genotype. Eur J Endocrinol. (2006) 155:229-36. doi: 10.1530/eje.1.02216

27. Kluijfhout WP, van Beek DJ, Verrijn Stuart AA, Lodewijk L, Valk GD, van der Zee DC, et al. Postoperative complications after prophylactic thyroidectomy for very young patients with multiple endocrine neoplasia type 2: retrospective cohort analysis. Medicine. (2015) 94:e1108. doi: 10.1097/MD.000000000000 1108

28. Machens A, Elwerr M, Lorenz K, Weber F, Dralle H. Long-term outcome of prophylactic thyroidectomy in children carrying RET germline mutations. Br J Surg. (2018) 105:e150-e7. doi: 10.1002/bjs.1 googleggoggl;kdsfmglsdgsdfsdfsd0746

29. Prete FP, Abdel-Aziz T, Morkane C, Brain C, Kurzawinski TR, Group MENiCUC. Prophylactic thyroidectomy in children with multiple endocrine neoplasia type 2. Br J Surg. (2018) 105:1319-27. doi: 10.1002/bjs.10856

Conflict of Interest: The authors declare that the research was conducted in the absence of any commercial or financial relationships that could be construed as a potential conflict of interest.

Copyright (C) 2020 Würgler Hansen, Sønderberg Roos, Løssl, Godballe and Mathiesen. This is an open-access article distributed under the terms of the Creative Commons Attribution License (CC BY). The use, distribution or reproduction in other forums is permitted, provided the original author(s) and the copyright owner(s) are credited and that the original publication in this journal is cited, in accordance with accepted academic practice. No use, distribution or reproduction is permitted which does not comply with these terms. 